\title{
The Moral Reasoning of Adolescent Boys and Girls in the Light of Gilligan's Theory
}

\author{
Farhat Kalsoom \\ M.Phil Scholar PMAS-Arid Agriculture University Rawalpindi, Pakistan \\ Malik Ghulam Behlol \\ Assistant Professor, Arid Agriculture University, Rawalpindi, Pakistan \\ E-mail: ghulam_behlol@yahoo.com \\ Muhammad Munir Kayani \\ Assistant Professor, IIUI, Pakistan \\ Aneesa Kaini \\ Visiting Faculty IIUI, Pakistan
}

Received: January 4, 2012 Accepted: January 17, 2012 Online Published: April 17, 2012

doi:10.5539/ies.v5n3p15

URL: http://dx.doi.org/10.5539/ies.v5n3p15

\begin{abstract}
The study was conducted to assess the moral reasoning of adolescent boys and girls in the light of Gilligan theory. The main objectives of the study were to investigate the moral reasoning of adolescent boys and girls with reference to responsibility orientation versus justice orientation and to compare the frequency of adolescent boys and girls with right orientation and responsibility orientation. The population of study consisted of all adolescent boys and girls studying in SSC and F.A/FSc of Fazaia Inter College Chaklala Rawalpindi. They all were sixteen to twenty years of age. The sample of study consisted of 40 boys and 40 girls studying in Matric and F.A/FSc of Fazaia Inter College Chaklala Rawalpindi, were taken applying random sampling technique. The scale developed by Baker and Role (2002), an objective measure of the two orientations was translated into Urdu language for the collection of the data of the study. The main conclusions of the study were that adolescent girls found to be more care oriented than boys, however, they were found to be equal on justice oriented. It was also inferred that religion is the most important factor which influence the moral judgment and justice oriented approach of boys and girls. The present study partially supports Gilligan's theory and it was also concluded that cultural norms do play an important role to make the boys more assertive to boys as compared to girls. It is expected from girls that they should be submissive, introvert and caring as compared to boys.
\end{abstract}

Keywords: Moral development, Gilligan theory, Investigation

\section{Introduction}

Morality is a system of beliefs, values, and underlying judgments about the rightness or wrongness of acts which the psychologists call conscience. The conscience is an internalized set of moral values (Craig, 1989; Zimbardo, 1988, p87). According to Piaget (1965) morality is an individual's respect for the rules of social order and his sense of justice, where justice is a concern for reciprocity and equality among individuals. Moral development theory given by Piaget concerns developmental changes in thinking based on his observation of children playing marble. Piaget revealed that moral reasoning changes significantly from early childhood to adolescence that appear to be orderly and predictable way that they roughly coincide with developmental changes in thinking. Kohlberg noted that there was not the age related consistency in moral judgment predicted by Piaget's theory. Kohlberg subsequently developed a model of moral reasoning having levels of moral development. At stage 1 the obedience and punishment orientation: children make choices based on principles of avoiding punishment and obeying authority figure. In stage 2 native hedonistic and instrumental orientation: choices are based on the principle of 
self-satisfaction. In stage 3 the good boy/girl orientation: children make choices reflecting a desire for the approval of others. At stage 4 law and authority orientation: the decisions reflect a sense of duty to obey recognized authority and the avoidance of action that might under-mine the social order. In stage 5 social contract orientation: concern is focused on balancing the value of social stability with the right of the individual. At stage 6, universal ethical principle orientations: decisions are backed on conscience and principle such as justice, reciprocity, human rights rather than law is condemned.

Gilligan argues that Kohlberg's stages theory needs to include the female perspective along with the male (Craig, 1989, p. 354-355). Gilligan suggests that males and females are taught different values as they develop and argue that men and women develop differently, but neither can be said to be more or less morally developed than the other. Women develop morally through caring of others, while men develop morally through a sense of justice (Zimbardo, 1985). Gilligan viewed women as progressing from initial selfishness (first level) to caring primarily for others (second level) and finally to an integration of concern for the needs of both self and others (third level). Their moral responsibility emphasizes attachments, allows for both self-sacrifice and selfishness, and considers connections with others. While Kohlberg's morality of justice emphasizes on autonomy, rules, legalities, and considers the individual as primary. Gilligan and Attanucci (1988) have stressed that neither orientation is superior; rather, care and justice are complementary. As a result of this, it was a decided to conduct a study of the moral development of the male and female adolescent boys and girls in the light of Gilligan's theory. The study is also important in Pakistan because little research seems to have been done on this topic, especially with reference to cross-cultural validation of Moral justification Scale in Pakistan. The study results will be beneficial for the teachers of adolescent boys and girls in improving religious and moral education to this age group

\section{Review of Literature}

Development means the qualitative change in the body and their consequent behavior maturity. Anderson's stance about development is that it is the network of interrelated task and process that provide footing of further maturity. Development is the "maturation" of thoughts, feeling personality social relationship, body and motor skill, compared with growth which is the rate of development. Moral development investigates how children evolve a sense of right and wrong, good and bad, and how adults hone their abilities to handle ethical issues in daily life. This includes resolving value conflicts, fermenting rusting cooperative and tolerant relationships and setting ethical goals. It focuses most on how we think about these ethical issues and how we act as result.

According to Piaget (1932) heteronymous morality is the first stage of moral development and it lasts from approximately 4 to 7 years of age. Justice and rules are conceived as unchangeable properties of the world, removed from the conical of people. Autonomous morality is Piaget's second stage of moral development reached at about 10 years of elder. At this point, the child becomes aware that rules and laws are created by people and that in judging an action the actors intention as well as the consequences should be considered. Children 7 to 10 years of age are in a transition between the two stages. Young children believe that a violation is in some way automatically connected to punishment. They often look around in a worried fashion after committing transgression, expecting inevitable punishment. Older children, being moral autonomies recognize that punishment is socially medicated and occurs only if a relevant person witnesses the wrong doing and that even then punishment is not inevitable. Piaget said that moral development is mainly advanced thought of mutual give and take of peer relations in the peer group where all members have similar power and statues, rules are negotiated and disagreement reasoned about and eventually settled. In Piaget's view, parents play less important role in children's moral development because they have so much more power than children and hand down rules in an authoritarian way. (Santrock 2001)

According to Kohlberg $(1958,1976,1986)$ moral development is based primarily on moral reasoning and unfolds in a series of stages. He arrived at his view after about 20 years of research involving unique interviews with individuals of different ages. In the interviews, children were presented with a series of stories in which characters faced moral dilemmas. In Europe a woman was near death from a special kind of cancer and there was one drug that the doctor thought might save her. It was a form of radium that a druggist in the same town had recently discovered. The drug was expensive to make, but the druggist was charging ten times higher what the drug cost him to make. He paid \$200 for the radium and charged \$2000 for a small doze of the drug. The sick woman's husband Heiz went to everyone and only managed $\$ 1000$, which half of what it cost. He told the druggist that his wife was dying and asked him to sell it cheaper or let him pay later, but the druggist said "No, I discovered the drug and I am going to make money from it". So Heiz got desperate and broke into the men's store to steal the drug for his wife. After reading the story, in the case of young children hearing it read to them individuals are asked a series of questions such as: Was Heiz right to steal the drug? Is it a husband duty to steal the drug? Would a good husband steal? Did the druggist have the right to charge so much for the drug? Why or why not? 
Kohlberg identified three levels and six stages of moral development. At pre-conventional level, there are two stages such as Obedience and Punishment Orientation, Individual and Exchange. Obedience and Punishment Orientation stage is similar to Piaget's first stage of moral thought. The child assumes that powerful authorities hand down a fixed set of rules which he or she must unquestioningly obey. To the Heinz dilemma, the child typically says that Heinz was wrong to steal the drug because "It's against the law," or "It's bad to steal" it. When asked to elaborate, the child usually responds in terms of the consequences involved, explaining that stealing is bad because you'll get punished (Kohlberg, 1958b). The vast majority of children at stage 1 oppose Heinz's theft. Even though the child agrees with Heinz's action, the reasoning is still stage1; the concern is with what authorities permit and punish. Kohlberg calls stage 1 thinking "Preconventional" because children do not yet speak as members of society. Instead, they see morality as something external to themselves, as that which the big people say they must do.

At Individual and Exchange stage children recognize that there is not just one right view that is handed down by the authorities. Different individuals have different viewpoints. Since everything is relative, each person is free to pursue his or her individual interests. One boy said that Heinz might steal the drug if he wanted his wife to live, but that he doesn't have to if he wants to marry someone younger and better-looking girl (Kohlberg, 1963, p.24). Another boy said Heinz might steal it because maybe they had children and he might need someone at home to look after them. But maybe he shouldn't steal it because they might put him in prison for more years than he could stand (Colby and Kauffman. 1983, p.300). What is right for Heinz, then, is what meets his own self-interests. You might have noticed that children at both stages 1 and 2 talk about punishment. However, they perceive it differently. At stage 1 punishment is tied up in the child's mind with wrongness; punishment "proves" that disobedience is wrong. At stage 2, in contrast, punishment is simply a risk that one naturally wants to avoid. Although stage 2 respondents sometimes sound amoral, they do have some sense of right action. This is a notion of fair exchange or fair deals. The philosophy is one of returning favors- - If you scratch my back, I'll scratch yours.” Respondents at stage 2 are still said to reason at the Preconventional level because they speak as isolated individuals rather than as members of society. They see individuals exchanging favors, but there is still no identification with the values of the family or community.

Level II: Conventional Morality. It begins with Stage 3 that is known by the name of Good interpersonal Relationships. At this stage, children who are by now usually entering their teens, see morality as more than simple deals. They believe that people should live up to the expectations of the family and community and behave in "good" ways. Good behavior means having good motives and interpersonal feelings such as love, empathy, trust, and concern for others. Heinz, they typically argue, was right to steal the drug because "He was a good man for wanting to save her," and "His intentions were good, that of saving the life of someone he loves." Even if Heinz doesn't love his wife, these subjects often say, he should steal the drug because "I don't think any husband should sit back and watch his wife ding” (Gibbs et al., 1983, pp. 36-42: Kohlberg, 1958b). It was really the druggist’s fault, he was unfair, trying to overcharge and letting someone die. Heinz loved his wife and wanted to save her. I think anyone would. I don't think they would put him in jail. The judge would look at all side, and see that the druggist was charging too much (Kohlberg, 1963p. 25). He talks about the loving husband, the unfair druggist, and the understanding judge. His answer deserves the label conventional morality because it assumes that the attitude expressed would be shared by the entire community — anyone would be right to do what Heinz did (Kohlberg, 1963, p. 25). As mentioned earlier, there are similarities between Kohlberg's first three stages and Piaget's two stages. In both sequences there is a shift from unquestioning obedience to a relativistic outlook and to a concern for good motives. For Kohlberg, however, these shifts occur in three stages rather than two.

Stage 4. Maintaining the Social Order. At stage 4, in contrast, the respondent becomes more broadly concerned with society as a whole. Now the emphasis is on obeying laws, respecting authority, and performing one's duties so that the social order is maintained. In response to the Heinz story, many subjects say that they understand that Heinz's motives were good, but they cannot condone the theft. What would happen if we all started breaking the laws whenever we felt we had a good reason? The result would be chaos; society couldn't function. As one subject explained, I don't want to sound like Spiro Agnew, law and order and wave the flag, but if everybody did as he wanted to do, set up his own beliefs as to right and wrong, then I think you would have chaos. The only thing I think we have in civilization nowadays in some sort of legal structure which people are sort of bound to follow. (Gibbs et al., 1983, pp. 140-41) Subjects make moral decisions from the perspective of society as a whole, they think from a full-fledged member-of-society perspective (Colby and Kohlberg, 1983, p. 27).

Level III. Post Conventional Morality. This level begins with Stage 5 by the name of Social Contact and Individual Rights: People want to keep society functioning. However, a smoothly functioning society is not necessarily a good one. A totalitarian society might be well-organized, but it is hardly the moral ideal. People begin 
to ask, "What makes for a good society?" They begin to think about society in a very theoretical way, stepping back from their own society and considering the rights and values that a society ought to uphold. They, then evaluate existing societies in terms of these prior considerations. They are said to take a "prior-to-society" perspective (Colby and Kohlberg, 1983, p. 22). They basically believe that a good society is best conceived as a social contract into which people freely enter to work toward the benefit of all they recognized that different social groups within a society will have different values, but they believe that all rational people would agree on two points. First they would all want certain basic rights, such as liberty and life, to be protected second, they would want some democratic procedures for changing unfair law and for improving society. In response to the Heinz dilemma, stage 5 , respondents make it clear that they do not generally favor breaking laws; laws are social contracts that we agree to uphold until we can change them by democratic means. Nevertheless, the wife's right to live is a moral right that must be protected. Morality and rights take some priority over particular laws.

Stage 6. Universal Principles. Respondents are working toward a conception of the good society that suggests that we need to (a) protect certain individual rights and (b) settle disputes through democratic processes. However, democratic processes alone do not always result in outcomes that we intuitively sense are just. A majority, for example, may vote for a law that hinders a minority. Kohlberg's conception of justice follows that of the philosophers Kant and Rawls, as well as great moral leaders such as Gandhi and Martin Luther King. According to these people, the principles of justice require us to treat the claims of all parties in impartial manners, respecting the basic dignity, of all people as individuals. The principles of justice are therefore universal; they apply to all. Thus, for example, we would not vote for a law that aids some people but hurts others. The principles of justice guide us toward decisions based on an equal respect of all. In actual practice, Kohlberg says, we can reach just decisions by looking at a situation through one another's eyes. Theoretically, one issue that distinguishes stage 5 from stage 6 is civil disobedience. Stage 5 would be more hesitant to endorse civil disobedience because of its commitment to the social contract and to changing laws through democratic agreements. Only when as individual right is clearly at stake does violating the law seem justified. At stage 6 , in contrast, a commitment to justice makes the rationale for civil disobedience stronger and broader. Martin Luther King, for example, argued that laws are only valid insofar as they are grounded in justice, and that a commitment to justice carries with it an obligation to disobey unjust laws. King also recognized, of course, the general need for laws and democratic processes (stage 4 and 5), and he was therefore willing to accept the penalties for his actions. Nevertheless, he believed that the higher principle of justice required civil disobedience (K 1981, p.43).

Kohlberg's theory has not gone unchallenged (Turiel, 1997) that moral thought don't always predict moral behavior. Theory places too much emphasis on moral thinking and not enough on moral behavior. No one wants a nation of Kohlberg's thinkers who know what is right yet do what is wrong. Simpson (1974), says that Kohlberg has developed a stage model based on the Western philosophical tradition and has applied this model to non-Western cultures without considering the different moral outlooks. It is also criticized that Kohlberg's theory is too individualistic, as Gilligan (1982-1998) distinguished between the justice prospective and the care perspective. His theory is a justice perspective that focuses on the rights of the individual, who stands alone and makes moral decisions. Emphasis is placed on relationships and concern for others according to Gilligan, Kohlberg greatly underplayed the care perspective, possibly because he was a male most of his research was on males and he lived in a male dominant society. Kohlberg studied the moral reasoning of males but not females. Gilligan believes that males and females in our society have different orientation towards moral issues because they go through different socialization processes. Males are encouraged to be independent and as serve, which causes them to perceive moral issues in terms of resolving conflicting interests by applying social rules concerning individuals rights females on the other hand are encouraged to be neutral, which causes them to perceive moral issues in terms of resolving conflict in ways that concern individuals responsibilities.

Gilligan Theory OF Moral Development: Kohlberg used hypothetical moral dilemmas in his studies, but Gilligan used a real life moral dilemma based on the moral reasoning of a group of pregnant women concerning the issues of abortion. Gilligan model not only describes level of moral development but also the changes that occur during the transition from one level to the next. She explained the theory in the form of three levels: Level 1: Orientation to Self-Survival: Initially women are oriented toward protecting their own self interests to advance in level II. They must go through a transitional phase in which recognize the same time there may be a conflict between doing what is good for themselves and doing what is the responsible thing to do. Level 2: Goodness as Self-Sacrifice: At this level women attempt to behave in a responsible manner avoiding doing harm to others when possible even through such behavior may involve self sacrifices. They must go through a transitional phase in which they begin to consider not only their responsibility to avoid hurting others but also their responsibility to avoid hurting themselves. Level 3: The Morality of Nonviolence: At this level women accept the principle of nonviolence as the basis underlying 
rationale of all moral behavior in making moral judgments they now consider avoiding harm to themselves just as important as was avoiding harm to others.

Gilligan's View of Adolescence as a Critical Juncture in the Development of Females: Gilligan and her colleague has conducted intensive interviews with girls from 6 to 18 years of age and reported that girls consistently reveal detailed knowledge about human relationship that is based on listening and watching what happens among people. They sensitively pick up different rhythms in relationship and often are able to follow the pathways of feelings. Gilligan believe that girls experience life differently than boys do. They come to a critical juncture in their development when they reach adolescence, and during early adolescence they are aware of the fact that their intense interest in intimacy is not prized by the male dominated culture even though society values women as caring and altruistic. Some critics argue that Gilligan and her colleagues overemphasize difference in gender and exaggerate the differences in intimacy and connectedness between males and females. They also pointed out that the research strategy which rarely includes a comparison group of boys doesn't provide realistic and valid analyses. She conducted extensive interviews only with girls to buttress her ideas. The critics also fear that Gilligan's findings reinforce stereotypes females as nurturing and sacrificing which might undermine females' struggle for equality. What we should be stressing, say these critics is more opportunities for females to reach higher level of achievement and self determination.

Gilligan (1990) concluded from her interviews that adolescence may be an especially critical time in females' development because it poses a problem to connection that is not easily resolved. She says that, as girls grow up in western culture, they face tradition in which "human" for the most part has meant "male". Thus as girls enter adolescence, they face a struggle with the masculine, autonomous wall of western culture. The data of interview revealed that girls experienced storms in relationship and pleasure in relationships about relational worlds through which at times seemed blocked or walled. They had a problem standing between her and her ability to achieve anywhere near her full potential. They did not know, if she would ever understand what her problem was, but that someday may be it would go away and then she would be happy. They felt that they should solve her problems by herself rather than share them with her friends. According to Gilligan, girls, wishes to make connections with other are reflected in the pleasure they find in relationships. For example, when Gilligan asked Molly whether she and her friend depended on each other, Molly said that they were so strong for each other because they had such a good time together, because they were so happy when they were her mother depended on each other.

Gilligan also believes that it is in close relationship, that adolescent girls are more willing to argue or disagree. One adolescent girls, Anna, told Gilligan that if you loved someone, you were usually comfortable enough with them to argue with them and say that you wanted them to see your side. Anna said, it was easier to fight with someone you loved because you knew that they would usually forgive you and would still be there after the disagreement. In an interview with another adolescent girl, Lisa, Gilligan asked, what is the most things that can happen in a relationship?" Lisa said that the worst thing would be not being able to talk to each other, especially if you depended on being able to talk to someone. In short, Gilligan and her colleagues found that communication in close relationships is especially important in the development of the female adolescents. (John W. Santrock, 1996)

Moral Education: The moral education of adolescents has become a widely discussed topic. Many parents worry that their adolescents are growing up without traditional values. Teachers complain that many of their students are unethical. Among the question about moral education we examine are: What is the hidden curriculum? What is the nature of direct moral education verses indirect moral education? What is values classification? What is cognitive moral education? How should we faster adolescent' moral growth? More than 60 years ago, educator John Dewey (1933) recognized that even when schools do not have specific programs in moral education, they provide moral education through a "hidden curriculum". The hidden curriculum is conveyed by the moral atmosphere that is a part of every school. Classroom rules and peer relation at school transmit attitudes about cheating, lying, stealing and consideration for others and through its rules and regulations the school administration infused the school with a value system.

Direct Moral Education involves either emphasizing values or character traits during specified time slots or integrating those values or traits throughout the curriculum. Indirect Moral Education involves encouraging adolescents to define their own, other values and helping them to define them in moral perspectives that support those values. Character Education is a direct approach to moral education that involves teaching students basic moral literacy to prevent them from engaging in immoral behavior and doing harm to themselves or others. The arguments is that behaviors such as lying, stealing and cheating are wrong and that students should be taught this throughout their education. Every school should have an explicit moral code that is clearly communicated to students. Any violation of the code should be not with sanctions (Bennett, 1993). Instruction in moral concepts with respect to specific behaviors, like cheating can take the form of example and definition, class discussions and role 
playing, or rewarding students for proper behavior. Some character education movements are the character education partnership.

Values clarification means helping people to clarify what their lives are for and what is worth working for. In this approach, students are encouraged to define their own values and to understand the values of others. Values clarification differs from character education in not telling students what their valued should be. In the following valued clarification example, students are asked to select, from among ten people, the six who will be admitted to a safe shelter because a third world war had broken out (Johnson, 1990). The choices are: A 30 years old male bookkeeper, the bookkeeper's wife, who is six months pregnant, A second year old African American male medical student who is political activist, A 42 years old male who is a famous historian author, A Hollywood actress who is a singer and dancer, A female biochemist, A 54 years old male Rabbi, A male Olympic athlete who is good in all sports, A female college student and A policeman with a gun. In this type of values clarification exercise, these are no right or wrong answers. The clarification of values is left up to the individual student. Advocates of values clarification say it is value free. However, critics say that controversial content offends community standards.

Cognitive Moral Education: Cognitive moral education is an approach based on the belief that students should learn to value things like democracy and justice as their reasoning develops. Kohlberg's theory has been the basis for a number of cognitive moral education programs. In a typical program, high school students meet in a semester long course to discuss a number of moral issues. The instructor acts as a facilitator rather than as a director of the class. The hope is that the students will develop more advanced notions of such concepts as cooperation, trust, responsibility, and community. Kohlberg (1998) recognized that the moral atmosphere of the school is more important than he initially envisioned. For example in one of the study, a semester long moral education class based on Kohlberg's theory was successful in advancing moral thinking in three democratic schools but not in those authoritarian schools (Higgins, Poser and Kohlberg,1983).

Miller () conducted study dealing with cultural influences on moral reasoning, Kohlberg's logic upon which his stages of moral development is based is argued. Kohlberg's levels of development are concerned with issues of justice and goodness. Thus, a cross-cultural study between Americans and Indians was conducted to examine any systematic differences between the two types of reasoning. These two groups were chosen because of the diversity of cultural beliefs and values, which have and effect on views of interpersonal responsibilities. A total sample of 120 subjects was selected from the U.S. and from a city in southern India and the American group generally held a Christian background, whereas the Indian group generally maintained traditional Hindu beliefs and customs. Subjects were presented with situations which dealt with breaches of justice and interpersonal relations. The results confirmed the hypotheses that there exist cultural differences in judging moral situations through interpersonal responsibility or in terms of justice concerns. Indians more frequently resolved situations in terms of alternatives dealing with relations between people. In addition, Americans rated solutions of justice as more desirable that interpersonal choices. The researchers argue that in the Indian framework obligations between individuals might be viewed as paramount in comparison to justice obligations when individuals are assessing moral behavior. From these findings it seems that moral reasoning is partially culturally bound, and the researchers argue that his method of reasoning is not inferior to Kohlberg's reasoning on justice.

Researchers continued to ask questions dealing with cultural influences on moral development. Do cultural influences have an effect on moral reasoning and judgment? In addition, researchers continued to use American and Indian subjects as comparison groups because of the distinct cultural differences. Due to what each culture emphasizes in its social framework, the researchers were interested in how individuals explained behavior, as influenced by situational factors or personal choice. In addition they wanted to assess how readily one is willing to forgive behaviors. In the method of this study, subjects were asked to make moral judgments on hypothetical question of justice (Bersoff \& Miller, 665). The hypothetical included evaluating: a 10 year-old child's behavior, an act performed under anger or fear that was provoked by the situation, and lastly by an individual in an accident. Due to the Indians emphasis in the culture on situational influences, the researchers hypothesized that Indians would hold individuals less accountable for actions the anger and accident scenarios. The results demonstrated to support the hypothesis that Indians are more likely to "absolve" individuals for their actions (Bersoff \& Miller, 672). Despite the cultural influences, subjects tended to "absolve" most individuals in the accident condition, and then followed with less in the anger condition and fewer in the behavior of the "immature" 10 year-old (Bersoff \& Miller). This finding may emphasize that some overlap may exist in how cultures perceive influences on behavior.

\section{Gender Effects on Moral Development}

Carol Gilligan's critique of Kohlberg's theory of development asked researchers to assess if gender or even gender role has an effect on moral judgment. A recent study on moral situations, gender, and gender role was conducted in 
order to provide some empirical data for the theories on moral development. It is presently unclear in moral judgment research between genders, if gender differences exist due to the internal model from which judgments are claimed to derive from or because judgments are made from different moral situations (Wark \& Krebs, 221). The researchers predicted that if Gilligan's perspective on Kohlberg's model is valid then females and feminine persons should make more stage 3, care based judgments, than males and masculine persons. In addition, if Gilligan's perspective is valid, female and feminine persons should make more care based judgments across moral situations and males and masculine persons should make more justice based judgments across situations (Wark \& Krebs, 221). The results of the study did not validate Gilligan's perspective in gender and gender role differences in moral judgments (Wark \& Krebs, 227). Members of both genders made more justice judgments relative to care judgments. In addition, the study did not support one of the foundational assumptions of Kohlberg and Gilligan which claimed that moral judgments are derived from some internal model which is consistent across situations. In the study $85 \%$ of the subjects made judgments based on three substages of Kohlberg's theory, and a quarter of the subjects made judgments ranging among five substages of moral thinking (Wark \& Krebs, 228)

\section{Objectives of the Study}

The objectives of the study were:

1) To investigate the moral reasoning of adolescent boys and girls with reference to responsibility orientation versus justice orientation.

2) To compare the frequency of adolescent boys and girls with right orientation and responsibility orientation.

3) To explore the validity of the moral justification scale in Pakistan.

\section{Research Hypotheses of the Study}

The following research hypotheses were derived from Gilligan theory;

1) There is no significant difference between the mean care orientation scores of boys and girls.

2) There is no significant difference between the mean justice orientation scores of boys and girls.

\section{Method and Procedure of the Study}

The population of study consisted of all adolescent boys and girls studying in SSC and F.A/FSc of Fazaia Inter College Chaklala Rawalpindi. The population had homogeneous characteristics coming from middle and lower middle class families. They all were sixteen to twenty years of age. The sample of study consisted of 40 boys and 40 girls studying in Matric and F.A/FSc of fazaia inter college Chaklala Rawalpindi. The institution was selected applying purposive sampling technique because the college administration was cooperative and allowed to conduct the study. The students from boys and girls were taken applying random sampling technique and every member of the population had the equal chance of being selection. The sampling frame is given in Table 3.

Insert Table 3 about here.

The scale developed by Baker and Role (2002), an objective measure of the two orientations was consisted of six vignettes, of which two were justice oriented, two were care oriented and two were mixed, incorporating both orientations. As two of these dilemmas were not suited to our culture, they were modified according to Pakistani culture and values and their approval was obtained from the author. All the dilemmas, six male versions and six female versions were translated into Urdu (Appendix 'B'). Moral justification Scale was an easily administered, objectively scored measure of Gilligan's constructs of care and justice.

First the adolescent boys and girls were identified with respect to their classes of Fazaia Inter College Chaklala Rawalpindi. Eight groups of boys and eight groups of girls of eighty students were made. Each group of girls included five girls and each group of boys included five boys. The researcher read one dilemma to each group of five boys or each group of five girls for their understanding and then every individual was asked to give their responses on a ten point scale given at the end. Data collection procedure was completed in six to seven weeks. Scoring was done according to the scoring procedure given by Baker and Role which guides, what item scores are added up to given scores on each subscale. The scores on three care subscales were added to get total care score and three justice subscales were added to get total justice score. Total care score of girls and total care of boys, total justice score of girls and total justice score of boys were collected. Mean, Standard deviation, $\mathrm{Q}_{1}, \mathrm{Q}_{3}, \mathrm{~T}$ test was applied to test the study hypotheses in order to find the difference between the mean justice and care scores of adolescent boys and girls. The level of significant used in study was 0.05 levels.

\section{Analysis and Interpretation of Data}

Insert Table 1 here 
As the entries in the above table indicate, the actual difference between the mean care score of adolescent boys and girls was found to be 25.4. The mean of the two groups were 133.9 and 159.5 was respectively. The SD of the boys group was 12.31 and of girls was 24.3. When the $t$ test was applied, the $t$ value was 22.46 . This value is statistically significant not only at .05 level of significance but also at .001 level. The null hypothesis that there is no Significance of difference between the mean of care scores of Adolescent boys and girls was rejected, and it was concluded that significant difference does exist.

Insert Table 2 here

As the entries in the Table 2 indicate that the actual difference between the mean justice scores of adolescent boys and girls was found to be 0.7. The mean of the two groups were 167.1 and 167.8 was respectively. The SD of the boys group was 32.4 and of girls was 27.7 . When $t$ test was applied, the t value was 0.38 , which is statistically non significant at point .05 level of significance. The null hypothesis that there is no Significance of difference between the mean of justice scores of Adolescent boys and girls was retained, and it was concluded that significant difference does not exist. The null hypothesis No.2 is therefore retained.

\section{Conclusions}

The purpose of study was to investigate the moral reasoning of adolescent boys and girls on Gilligan's theory. The main objective of the study was to investigate the moral reasoning of adolescent boys and girls with reference to responsibility orientation versus justice orientation. Adolescent girls found to be more care oriented than boys because of their moral development and grooming due to the cultural environment in which they are brought up. There are different walls established by the cultural norms that make them behave in more care oriented way.

Adolescent boys and girls, however, were found to be equal on justice oriented. Through class discussion, students may be forced to face the contradictions present in any course of action and change their orientation by listening to other class fellows, leading to their moral decision making and judgment to the next higher stage. It has been inferred that religion is the most important factor which influence the moral judgment and justice oriented approach of boys and girls.

The present study partially supports Gilligan's theory. It has been observed that cultural norms play an important role to make the boys more assertive to boys as compared to girls. Socialization patterns of both are different. It is expected from girls that they should be submissive, introvert and caring as compared to boys. It may be due to small sample which consisted of only 40 students. For verification and validation of this theory large samples may be used in future studies. In the present study the sample was taken only from the Gulberg town and chaklala. There is no significant difference in their way of living. For further research, sample may be taken from different cross-cultural areas representing the various social classes such as the poor as well as the affluent status of the society.

\section{References}

Anne C, Gibbs, J. Lieberman, M., \& Kohlberg, L. (1983). A Longitudinal study of moral Judgment: A Monograph for the Society of Research in Child Development. The University of Chicago Press

Craig, G. J. (1989). Human Development ( $5^{\text {th }}$ ed.). Englewood Cliffs, NJ: Prentice Hall.

Gay, L.R. (1990). Educational research: Competencies for analysis and application. New York: Macmillan publishing company.

Gilligan, C. (1977). In a different voice: women's conceptions of self and morality". Harvard Educational Review 47 (4).

Kohlberg, Lawrence, Charles, L., \& Alexandra, H. (1983). Moral stages: a current formulation and a response to critics. Basel, NY: Karger

Kohlberg, Lawrence (1981). Essays on moral development: The Philosophy of Moral Development. San Francisco, CA: Harper \& Row.

Piaget, J. (1932). The moral judgement of the child. NY: Harcourt, Brace Jovanovich.

Rawls, J. (1971). A theory of justice. Cambridge, MA: Belkap Press of Harvard University Press.

Rest, J., Narvaez, D., Bebeau, M., \& Thoma, S. (1973). Postconventional moral thinking: A Neo-Kohlbergian Approach. Mahwah, NJ: Lawrence Erlbaum Associates.

Santrock, J. W. (2001). Educayional psychology, Boston: Mc Graw_Hill.

SW.C. C. (1985). Theories of Development. Prentice-Hall.

Zimbardo, P. (1988). Psychology and life (12th Ed.). Glenview IL: Scott, Foresman and Co. 
Table 1. Significance of difference between the mean of care scores of Adolescent boys and girls

\begin{tabular}{|l|l|l|l|l|l|}
\hline Category & $\mathbf{X}$ & SD & SED & $\mathbf{t}$ & P \\
\hline Boys & 133.9 & 12.31 & \multirow{2}{*}{1.14} & 22.46 & $<.001$ \\
\hline Girls & 159.5 & 24.03 & & & \\
\hline
\end{tabular}

Table 2. Significance of difference between the mean justice scores of Adolescent boys and girls

\begin{tabular}{|l|l|l|l|l|l|}
\hline Category & $\mathbf{X}$ & SD & SED & t & P \\
\hline Boys & 167.15 & 32.42 & 1.74 & 0.38 & $>.05$ \\
\cline { 1 - 3 } & 167.8 & 27.77 & & & \\
\hline
\end{tabular}

$\mathrm{df}=38 \quad \mathrm{t}$ at $.05=2.0$

Table 3.

\begin{tabular}{|l|l|l|}
\hline Levels of Education & Boys & Girls \\
\hline SSC & 20 & 20 \\
\hline F.A/F.Sc & 20 & 20 \\
\hline
\end{tabular}

